\title{
Effectiveness of Tax Credits for Health Insurance Premium: Evidence from the Health Insurance Tax Credit
}

\begin{abstract}
With the push to repeal the Affordable Care Act (ACA), there is renewed interest in using tax credits to increase health insurance coverage. Another tax credit-driven policy, the Health Insurance Tax Credit (HITC), was implemented during 1991-1993. To date, only one paper, Cebi \& Woodbury (2014), has analyzed the effectiveness of the HITC on coverage rates. In this paper, I reexamine the effectiveness of the HITC by using the Survey of Income Program Participation (SIPP) and provide the first estimates of its effects on utilization and self-reported health status. Despite using the different data set, I find a similar result regarding coverage as the previous paper - the effect of the HITC was about 5.8 percentage points. I also find that self-reported health was significantly improved due to the HITC. I conclude by discussing the implications of these findings on the larger debate regarding current health-care reform.
\end{abstract}

Keywords: Health Insurance, Tax Credits

JEL Classification: I13, H2

This is the author manuscript accepted for publication and has undergone full peer review but has not been through the copyediting, typesetting, pagination and proofreading process, which may lead to differences between this version and the Version of Record. Please cite this article as doi: $10.1002 /$ hec.3785 


\section{Introduction}

Health insurance access and affordability continues to dominate the political landscape in the United States. Since the beginning of the Trump administration, a significant component of the debate is to repeal and replace the Affordable Care Act (ACA), a government-led health policy enacted in 2010. For instance, the GOP tax bill that was recently passed includes getting rid of the individual mandate under the ACA. As a result, there are substantial fears that this change, alongside others, could increase premiums as healthy individuals will exit the market. A common method to reduce the burden of premiums, and thus encourage takeup, is using tax credits.

In this paper, I revisit the effectiveness of tax credits that were intended to promote coverage take-up and health-care utilization by examining the implementation and repeal of the Health Insurance Tax Credit (HITC). The overall circumstances of tax credits offered under the HITC differ from current laws and proposals but still provide a natural experimental setting to explore the effectiveness of tax credits on health insurance coverage and other health-related outcomes. $]^{1}$ To date, only Cebi and Woodbury (2014, hereafter CW) has explored the effectiveness of the HITC, but they solely examined the aspect of change in health insurance.

This paper begins by replicating CW based on a different data set, the Survey of Income and Program Participation (SIPP). I find a 7.1 percentage points (pp) increase in private health insurance coverage for low-educated, working single mothers due to the HITC combined with the Earned Income Tax Credit (EITC). This result is somewhat larger than the 4.7 pp increase found by CW using the Current Population Survey (CPS). I extend the analysis to the policy change in 1994-1995 (when the EITC was expanded and the HITC was

\footnotetext{
${ }^{1}$ With the HITC, some people were given tax credits for which they were not eligible before. In contrast, the most currently proposed bills [e.g., American Health Care Act (AHCA), Better Care Reconciliation Act (BCBA), Obamacare Repeal Reconciliation Act (ORRA) and Health Care Freedom Act (HCFA)] often suggest reducing those tax credits.
} 
repealed) to disentangle the effect of the EITC from that of the HITC. $2^{2}$ This analysis suggests that the effect of the HITC alone is $5.8 \mathrm{pp}$ while CW concluded $3.6 \mathrm{pp}$ by using a different DDD approach $3^{3}$ Given the consistency of my results with the previous paper, this paper assures the effectiveness of the HITC on coverage. I also estimate the effect of the HITC on health-care utilization and health status, finding a statistically significant improvement in health status 4

\section{Methods}

\subsection{Empirical Strategy}

The HITC was a supplement to the EITC from 1991 through 1993 and was introduced as part of the Omnibus Budget Reconciliation Act of 1990. It was a refundable tax credit available to EITC-eligible taxpayers who purchased private health insurance and had at least one child covered. The HITC was structured to vary by earned income.5

To examine how the adoption of the HITC with a parallel increase in the EITC affected single mothers, I first follow a difference-in-differences (DD) strategy used in CW by assessing changes in the 1991-1993 policy that simultaneously implemented the HITC and expanded the EITC, compared to 1989-1990. This strategy estimates the effect of the HITC combined with the EITC by comparing the average change in the outcomes for the treatment group with that of the control group. $]^{6}$ As in CW, my treatment group is working single mothers not

\footnotetext{
${ }^{2}$ The increase in the maximum amount of credits through the EITC (by $\$ 239$ in 1991, $\$ 132$ in 1992 and $\$ 110$ in 1993) has the potential to elevate the demand for health insurance. Therefore, it is problematic to identify the effect of the HITC per se on coverage without considering the policy change in 1994-1995.

${ }^{3}$ While my analysis is based on 1989-1995, CW instead enlarges the sample by adding earlier years going back to 1985 to isolate the effect of the HITC.

${ }^{4}$ It is reasonable to hypothesize that if low-income populations experienced a significant increase in insurance enrollment, then the effects of health-care utilization and health status in the active-HITC period might have subsequently increased.

${ }^{5}$ For example, if annual income was between $\$ 1$ and $\$ 7,140$, the credit was 6 percent of income. If one's income was between $\$ 7,140$ and $\$ 11,250$, the credit stayed constant at $\$ 428$. The credit gradually decreased to zero at the income-level of $\$ 21,250$. The average amount received by HITC-qualified individuals was about 23 percent of the overall average cost for health insurance premiums (GAO, 1994).

${ }^{6}$ The DD assumes that the trend in outcomes for both groups would have been the same without the 1991-1993 policy. Therefore, any deviation from this trend is attributed to the 1991-1993 policy.
} 
exceeding a high school education and the control group is working single women (without children) not exceeding a high school education.

My primary outcome of interest, private health insurance coverage, is based on the following SIPP questions:

- (1) 'Was the respondent covered by a private health insurance plan specifically under her own name?'

- (2) 'Was this individual-type plan covering only the respondent?'

- (3) 'Was this family-type plan covering all of the children in the respondent's family?'

Single women without children (the control group) are defined as covered if they answered 'yes' to the first two questions. Single mothers with children (the treatment group) are defined as covered if they answered 'yes' to the first and third questions..$^{7}$ In the baseline specification, I use the same linear probability model as CW (OLS):

$$
y_{i s t}=\beta_{0}+\beta_{1} * \text { Treat }_{i s t}+\beta_{2} * \mathbb{1}(t=91,92,93)_{t}+\beta_{3} * \text { Treat } * \mathbb{1}(t=91,92,93)_{i s t}+\beta_{4} * Z_{i s t}+\epsilon_{i t}
$$

where $\mathrm{i}, \mathrm{t}$ and $\mathrm{s}$ index individual, time (year) and state, respectively. The outcome variables of interest, $y_{i s t}$, are binary variables indicating whether the individual [1] 'was covered by private health insurance under the respondent's name,' [2] 'had visited a physician at least once in the previous year,' and [3] 'had a health status that was good, very good, or excellent.' Treat $_{i s t}$ represents an indicator for a single mother. $\mathbb{1}(t=91,92,93)_{t}$ is a dummy for the years 1991 to 1993 . Treat $* \mathbb{1}(t=91,92,93)_{\text {ist }}$ is equal to unity only if she was in the treatment group and the tax year is 1991, 1992 or 1993 . The estimate of $\beta_{3}$ denotes the effect of the 1991-1993 policy, the combined effect of the HITC and the EITC. $Z_{\text {ist }}$ includes

\footnotetext{
${ }^{7}$ One advantage of the SIPP is that it has information about the type of health insurance: individual or family. Despite this, due to limitations of the data (e.g., in 1989, subsequent questions of health insurance only asked whether it covers 'all' or 'only the respondent'), I consider the treatment group to be covered only if her family coverage accommodates 'every child in her family.' Therefore, the findings below may be conservative estimates of the effects of the HITC because mothers whose family plans only covered one of their children might not be considered as covered.
} 
same controls as used in CW 8

Although estimating (1) provides useful information about the HITC combined with the EITC, $\beta_{3}$, I wish to esatimte the effect of the HITC in isolation of the EITC. While CW also extends their analysis to isolate the HITC effect, their Difference-in-Difference-in-Differences (DDD) does not work with my data.9 Instead, I conduct a different DDD by further including the information from 1994 to 1995 when the HITC was repealed and the EITC was expanded again. 10 Including the additional information from 1994 to 1995 enables me to net out the possible influence of the EITC. Specifically, I estimate the model below:

$$
\begin{aligned}
y_{\text {ist }}=\delta_{0}+\delta_{1} * \text { Treat }_{\text {ist }}+ & \delta_{2} * \mathbb{1}(t=91,92,93)_{t}+\delta_{3} * \mathbb{1}(t=94,95)_{t}+ \\
& \delta_{4} * \text { Treat }
\end{aligned}
$$

The only change in $(2)$ is that $\mathbb{1}(t=94,95)_{t}$ and Treat $* \mathbb{1}(t=94,95)_{\text {ist }}$ are now included.11

While $\delta_{4}$ estimates the change in coverage among single mothers from 1991 to 1993, relative to $1989-1990, \delta_{5}$ estimates the change in coverage among single mothers from 1994 to 1995 , relative to 1989-1990. With an additional assumption that the 1994-1995 EITC expansion had the same impact as that of 1991-1993, the change attributed solely to the HITC can be estimated as $\delta_{4}-\frac{\delta_{5}}{2} \cdot 12$

\footnotetext{
${ }^{8}$ This includes race, age, categories of monthly total earned income that are converted to 1989 dollars $(<\$ 500, \$ 500-\$ 1000, \$ 1000-\$ 1500, \$ 1500-\$ 2000,>\$ 2000)$, work status (Full-time/Full-month, Part-time/Fullmonth, Full-time/Part-month, Part-time/Part-month) and number of children in the household. I also control for state-fixed effects, state unemployment rates $\left(U R T_{s t}\right)$ and the interaction of $\left(U R T_{s t}\right)$ with the treatment group indicator.

${ }^{9}$ In the SIPP, the main questionnaire was changed before and after 1989 (e.g., the SIPP explicitly asked, "whether a respondent has private health insurance" in 1989 onwards, whereas it asked more generally, "whether a respondent has health insurance" before 1989).

${ }^{10}$ Congress passed the OBRA of 1993 with an enactment of the largest EITC expansion in history (e.g., a mother with one child could receive a maximum credit of $\$ 1434$ in 1993 , while the maximum credit increased to $\$ 2038$ in 1994).

${ }^{11}$ The sample now has 1989-1995 time frame.

${ }^{12}$ To see why this quantity is an estimate of the HITC only, denote the 1991-1993 EITC effect on coverage as $a_{1}$, the HITC effect on coverage as $a_{2}$ and the 1994-1995 EITC effect on coverage $a_{3}$. Then, I can rewrite $\delta_{4}=a_{1}+a_{2}$ and $\delta_{5}=\left(a_{1}+a_{2}\right)+\left(a_{3}-a_{2}\right)$. The first term on the right-hand side (RHS) of $\delta_{5}$ is the effect of the 1991-1993 policy and the second term on the RHS represents the subsequent change in 1994-1995. With
} 


\subsection{Data}

I use data from the SIPP. Households are interviewed once every four months and asked questions about the previous four months. Within each SIPP panel, the sample is randomly divided into four rotation groups. One rotation group is interviewed each month and after all rotation groups complete their first interview, the first wave of the panel concludes. This continues typically for eight waves of each panel over the course of three years. ${ }^{13}$ For each SIPP panel, I select a wave that represents each year from 1989 to 1995. I use single women drawn from the third wave of the 1989 to 1993 panels (September to December for each year). Responses from SIPP Panel-1993 wave 6 and wave 9 represent periods from September to December in 1994 and September to December in 1995, respectively ${ }^{14}$ Table 1 provides the descriptive statistics of the sample from 1989 to 199515

[Table 1 Inserted]

\section{Results}

\subsection{Coverage Rates}

Columns 2-3 in Table 2, representing results from (1), indicate that private health insurance coverage was greater by about $7.1 \mathrm{pp}$ than it otherwise would have been for single mothers from 1991 to $1993 .^{16}$ Even with a different data set, my results are very similar to that of an additional assumption that $a_{1}=a_{3}$, I can rewrite $\delta_{5}=2 a_{1}$. Therefore, $a_{2}=\delta_{4}-\frac{\delta_{5}}{2}$ measures the 'HITC effect on coverage.' All of this analysis is based on the assumption that the effect of removing the HITC, $-a_{2}$, is the negative of the effect of adding the HITC, $a_{2}$.

${ }^{13}$ Multistage-stratified sampling is the other important aspect of the SIPP. To take this into account, I report both the weighted (WLS) and unweighted (OLS) estimates of the linear regression analyses below in Table 2 and 4 . I only report the weighted estimates for the remaining tables.

${ }^{14}$ I use 6th and 9th interviews of individuals from SIPP-1993 Panel to examine the HITC repeal along with the EITC expansion in 1994-1995 as there was no new sample collected during these years.

${ }^{15}$ Table S.4 in the non-published appendix shows the changes in outcome variables of interests during this period.

${ }^{16}$ If I take the number of the HITC eligible families headed by working single mothers with low education from the 1991 CPS (i.e., 2,485,000) and the estimated coverage increase of about $7.1 \mathrm{pp}$, there would be an increase in enrollment by about 176,435 people who would have otherwise not enrolled in health insurance. 
CW that estimated an increase in coverage of about 4.7 pp due to the 1991-1993 policy. ${ }^{17}$

[Table 2 Inserted]

[Table 3 Inserted]

In Table 3, I verify the robustness of the results. First, there were statewide reforms [i.e., state Aid to Families with Dependent Children reforms (AFDC) and state-specific EITCs] that might have confounded the results. Since state AFDC reforms restricted the duration of welfare reliance, it resulted in eligibles getting into the labor force, often accompanied by health insurance. Therefore, I exclude states that instituted an AFDC reform and reestimate (1). The result in column 1 of Table 3 was similar to Table 2 , suggesting that the coverage increase was not mainly due to AFDC reforms. Because state-EITC benefits could also provide another source of variation for the impact of tax credits on coverage (Baughman, 2005), I exclude states that had their own specific-EITC benefits. The result in column 2 remains unchanged, thereby showing that state-specific EITCs are not a significant concern. With reference to Eissa and Hoynes (2006) that respondents might adjust their income to be eligible for the HITC, column 3 addresses this concern by re-estimating (1) without income being included 18

[Table 4 Inserted]

In an effort to isolate the HITC, Table 4 suggests that the HITC effect $\left(a_{2}=\delta_{4}-\frac{\delta_{5}}{2}\right)$ is about $5.8 \mathrm{pp}$ based on estimates from (2). Given the aforementioned DDD assumption, I conclude that about eighty percent $(5.8 / 7.1)$ of the $7.1 \mathrm{pp}$ increase in coverage of single mothers was associated with the HITC only, just as CW attributed three-quarters (3.6/4.7)

\footnotetext{
${ }^{17}$ In addition to this, S.1 Table in the non-published appendix shows the event history analysis where I dis-aggregated the HITC combined with the EITC effect by years to explore whether this had a similar magnitude in all three years. Further, leaving out the interaction term of 1989 and the treatment dummy, there was no significant pre-treatment effect in 1990, possibly supporting the validity of the common trend assumption.

${ }^{18}$ While I exclude income controls, I do consider education-level in column 3. Table S.2 and Table S.3 in the non-published appendix analyze two additional robustness checks. They assess whether the increase in private coverage is shifting either from the uninsured population or from the Medicaid enrollees. Both Tables S.2 and S.3 offer evidence that the combined effect of the HITC and the EITC from 1991 to 1993 was a result of the uninsured population obtaining private coverage.
} 
of the $4.7 \mathrm{pp}$ increase to it. ${ }^{19}$

\subsection{Health-Care Utilization and Health Status}

Using (1) with utilization as an outcome variable, columns 1-2 in Table 5 show the effect of the HITC along with the EITC on the probability of an office visit ${ }^{20}$ Columns 5-6 make use of the question regarding self-reported health to construct a binary measure for the outcome variable that represents a 'good, very good, or excellent health status. ${ }^{21}$ To disentangle the HITC effect only, I re-estimate (2) and the corresponding results can be found in columns 3-4 and 7-8.

[Table 5 Inserted]

Overall, Table 5 displays that gaining private coverage did not translate into a significant increase in office visits, but it might have improved single mothers' health status by about $4.6 \mathrm{pp}{ }^{22}$ This is consistent with recent findings on whether the coverage expansion under the ACA has affected health status ${ }^{23}$ As the likelihood of having 'at least one annual office visit' is not the only dimension to measure utilization, if there were more thorough measures, it would have been helpful to see the reason for improved health status during 1991-1993.24

\footnotetext{
${ }^{19}$ Here, I am treating the EITC-expansion effects, $a_{1}$ (1991-1993) and $a_{3}$ (1994-1995), as identical. However, as the EITC expansion in 1994 was larger than in 1991 (e.g., in 1994 the maximum EITC increased by $42.1 \%$ while in 1991 it increased by $25.1 \%$ ), it might be more reasonable to relax the assumption as $a_{3} \geq a_{1} \geq 0$. If so, the bounds on the HITC effect, $a_{2}$, would be $\left(\delta_{4}-\frac{\delta_{5}}{2}, \delta_{4}\right)$, which is $(5.8,7.0) \mathrm{pp}$.

${ }^{20}$ I define utilization as a physician's office visit at least once per year that represents the extensive margin effects on health-care demand. The primary reason for this is that the frequency of utilization could be confounded with the individual's health status, leading to biased estimates of the HITC along with the EITC effect on health-care utilization (Currie and Gruber, 1996). One way to mitigate this concern is explicitly focusing on preventive care (e.g., an office visit for a routine check-up that is recommended once a year). In other words, an absence of an office-visit per year suggests an inaccessibility to the health-care system, regardless of health status.

${ }^{21}$ Refer to notes under Table 5 for additional details.

${ }^{22}$ Since the economy suffered a recession in the early 1990s, it might be plausible that the general population experienced worsening health status as its consequence (Ruhm, 2000). Interestingly, Table 5 results indicate that the HITC might have mitigated this degrading trend.

${ }^{23}$ After the ACA's coverage expansion, there was an improvement in self-reported health status (Sommers et al., 2015; 2017).

${ }^{24}$ One possible mechanism might be, as a result of the coverage, people in the treatment group were more likely to have a primary doctor.
} 


\section{Conclusions}

For decades, disagreement over health-care policy has been a major concern, and if anything, that concern has grown with the enactment and potential repeal of the ACA. Given this, I revisit the effects of the HITC, the tax credit policy passed in the early 1990s, to provide a better evidentiary base for the usefulness of tax credits.

My estimates substantiate the findings of CW that the implementation of the HITC with the EITC increased the coverage by $7.1 \mathrm{pp}$. Also, I find that coverage was increased by 5.8 pp solely due to the HITC. These estimates are based on a data set distinct from CW, and as for isolating the HITC, a distinct strategy is constructed based on the HITC repeal and the EITC expansion. Although it was a significant increase, a magnitude of $5.8 \mathrm{pp}$ shows that the HITC was not large enough to encourage everyone to be insured. Even with the HITC and the EITC in place simultaneously, the uninsured rate was still around $16.4 \%$ in 1991 1993 (Cohen et al., 2009), implying that achieving universal health-care by only tax-credit schemes will be challenging. ${ }^{25}$

Moving beyond health insurance, my results indicate that the HITC improved selfreported health. This suggests that for low-income families, the inability to acquire coverage might be the primary barrier for improved health status. Considering all findings of the HITC, making tax credits available for low-income families, a relatively inexpensive mechanism to implement, can be effective to provide incentives for coverage take-up and to achieve better health (albeit, if appropriate regulations were enforced). With that said, the ultimate repeal of the HITC validates the fact that it could have been more effective if the appropriate regulations had been in place. ${ }^{26}$ As the U.S. is at the cusp of policy reforms, this paper

\footnotetext{
${ }^{25} \mathrm{~A}$ possible explanation for this small magnitude is that the modest amount of tax credits, relative to high premiums, was insufficient to incentivize eligible individuals to enroll in those benefits (GAO, 1994). The other possible explanations would be insufficient outreach and lack of publicity regarding the HITC. This problem is also documented with the ACA exchanges, as about half a million fewer people signed up for insurance in 2017. This number would have been higher with an equal level of publicity under the Obama Administration.

${ }^{26}$ Even when the market was mostly unregulated, the HITC still resulted in an increase of the coverage and improved health status in 1991-1993. However, the HITC did not specify minimum benefits that must be included in insurance plans (as in a recent replacement proposal- $\mathrm{AHCH}$ includes a clause about removing
} 
has provided timely insights into the various aspects of tax credits and their operation in conjunction with larger health-care policies.

10 Essential Health Benefit mandates), enabling insurance companies to sell valueless plans to tax-credit eligible candidates (Sanger-Katz, 2017). This ultimately resulted in its repeal despite the relative success. 


\section{References}

[1] Baughman, Reagan. (2005) Evaluating the Impact of the Earned Income Tax Credit on Health Insurance Coverage, National Tax Journal

[2] Cebi, Merve and Stephen A. Woodbury. (2014) Health Insurance Tax Credits, the Earned Income Tax Credit, and Health Insurance Coverage of Single Mothers., Health Economics $23(5)(2014): 501-515$.

[3] Cohen, Robin; Makuc, Diane; Bernstein, Amy; Bilheimer, Linda; Powell-Griner, Eve. (2009) Health Insurance Coverage Trends, 1959-200\%: Estimates from the National Health Interview Survey, National Health Statistics Reports

[4] Currie, Janet and Gruber, Jonathan. (1996) Health Insurance Eligibility, Utilization of Medicare, and Child Health., Quarterly Journal of Economics

[5] Eissa N, and Hoynes H. (2006) Behavioral Responses to Taxes: Lessons from the EITC and Labor Supply, Tax Policy and the Economy, Volume 20 (2006)

[6] Ruhm, Christopher. (2000)Are Recessions Good for Your Health?, The Quarterly Journal of Economics, Volume 115, Issue 2.

[7] Sanger-Katz, Margot (2017, March, 23),Late G.O.P. Proposal Could Mean Plans That Cover Aromatherapy but Not Chemotherapy, The New York Times

[8] Sommers BD, Gunja MZ, Finegold K, Musco T. (2015) Changes in self-reported insurance coverage, access to care, and health under the Affordable Care Act., Journal of the American Medical Association; 314:366-374

[9] Sommers BD, Gawande A, Baicker K. (2017) Health Insurance Coverage and HealthWhat the Recent Evidence Tells Us, The New England Journal of Medicine

[10] U.S. Government Accountability Office. (1994) Tax administration: health insurance tax credit participation rate was low., GAO/GGD-94-99. 


\section{CONFLICT OF INTEREST}

The author has no conflict of interest.

This article is protected by copyright. All rights reserved. 
Table 1: Summary Statistics for Low-Educated Working Single Women without Children and Single Mothers with Children, 1989-1995

\begin{tabular}{|c|c|c|}
\hline Variables & Single Women & Single Mothers \\
\hline Age (in years) & $\begin{array}{l}30.9 \\
(7.93)\end{array}$ & $\begin{array}{l}30.3 \\
(7.90)\end{array}$ \\
\hline$\% \mathrm{w} /<12$ years of education & $\begin{array}{l}.168 \\
(.374)\end{array}$ & $\begin{array}{l}.230 \\
(.420)\end{array}$ \\
\hline$\% \mathrm{w} /=12$ years of education & $\begin{array}{l}.831 \\
(.374)\end{array}$ & $\begin{array}{l}.769 \\
(.420)\end{array}$ \\
\hline Number of Kids & - & $\begin{array}{l}1.86 \\
(1.04)\end{array}$ \\
\hline$\%$ White & $\begin{array}{l}.833 \\
(.372)\end{array}$ & $\begin{array}{l}.755 \\
(.430)\end{array}$ \\
\hline$\%$ Black & $\begin{array}{l}.136 \\
(.343)\end{array}$ & $\begin{array}{l}.220 \\
(.414)\end{array}$ \\
\hline$\%$ Others & $\begin{array}{l}.029 \\
(.170)\end{array}$ & $\begin{array}{l}.024 \\
(.155)\end{array}$ \\
\hline$\%$ Full-time, Full-Month & $\begin{array}{l}.801 \\
(.398)\end{array}$ & $\begin{array}{l}.729 \\
(.444)\end{array}$ \\
\hline$\%$ Part-time, Full-Month & $\begin{array}{l}.168 \\
(.374)\end{array}$ & $\begin{array}{l}.231 \\
(.422)\end{array}$ \\
\hline$\%$ Full-time, Part-Month & $\begin{array}{l}.019 \\
(.137)\end{array}$ & $\begin{array}{l}.022 \\
(.149)\end{array}$ \\
\hline$\%$ Part-time, Part-Month & $\begin{array}{l}.010 \\
(.102)\end{array}$ & $\begin{array}{l}.015 \\
(.123)\end{array}$ \\
\hline Total Income (Monthly $\$$ & 1,254 & 1,123 \\
\hline At the time of the interview) & $(881)$ & $(713)$ \\
\hline \% Unemployment Rate in one's State & $\begin{array}{l}6.24 \\
(1.40)\end{array}$ & $\begin{array}{l}6.22 \\
(1.35)\end{array}$ \\
\hline Private Health Insurance under own name-covered & $\begin{array}{l}.634 \\
(.481)\end{array}$ & $\begin{array}{l}.128 \\
(.334)\end{array}$ \\
\hline Annual Office Visit (Extensive Marign; Any) & $\begin{array}{l}.704 \\
(.456)\end{array}$ & $\begin{array}{l}.671 \\
(.469)\end{array}$ \\
\hline Self-Reported health good/very good/excellent & $\begin{array}{l}.917 \\
(.275)\end{array}$ & $\begin{array}{l}.916 \\
(.276)\end{array}$ \\
\hline Observations & 2,279 & 4,216 \\
\hline
\end{tabular}

Notes: Standard deviations are in parentheses. The sample includes working single women aged 19 to 45 years with a high school degree or less. Full-time is for people who are employed more than 35 hours per week. Part-time is for people who are employed for less than 35 hours per week. Full-Month is for those who recorded '1,' ' 2 ' or ' 3 ' in the variable, Employment Status for month Range (ESR), representing a job for the 'entire month.' Part-Month is for people with an ESR value with ' 4 ' and ' 5 ' representing work which is less than one 'entire month.' The individuals who have ESR greater than ' 5 ' are excluded because they are unemployed for the corresponding month. Also, the sample drops individuals from several states if their states were combined into one category or their state codes changed over time (i.e., Mississippi, New Mexico, Iowa, Maine, Montana, North Dakota, Vermont, West Virginia, South Dakota, Alaska, Idaho and Wyoming). The sample only considers those who had a positive total monthly income. Dollar amounts are converted to 1989 dollars using $\boldsymbol{C P I - U}$. For respondents from SIPP Panel-1992 and 1995, the change in timing of questionnaires about health-care utilization/self-reported health status raises a concern. Therefore, I do not consider 1992 and 1995 for studying the impact of the HITC on health-care utilization and health status. $\left.{ }^{* * *} \mathrm{p}<0.01,{ }^{* *} \mathrm{p}<0.05,{ }^{*} \mathrm{p}<0.1\right)$ 
Table 2: Estimates from Equation (1), 1989-1993

\begin{tabular}{llll}
\hline Covered by Private Health Insurance & \multicolumn{1}{c}{$(1)$} & \multicolumn{1}{c}{$(2)$} & \multicolumn{1}{c}{$(3)$} \\
\hline & CW $(2014)$ & WLS & OLS \\
& & & \\
\hline Treat, $\beta_{1}$ & $-.128^{* * *}$ & $-.472^{* * *}$ & $-.468^{* * *}$ \\
& $(.024)$ & $(.072)$ & $(.069)$ \\
$\mathbb{1}(\mathrm{t}=91,92,93), \beta_{2}$ & $-.142^{* * *}$ & $-.079^{* *}$ & $-.091^{* * *}$ \\
& $(.001)$ & $(.032)$ & $(.029)$ \\
Treat* $\mathbb{1}(\mathrm{t}=91,92,93), \beta_{3}$ & $.047^{* * *}$ & $.071^{*}$ & $.081^{* *}$ \\
& $(.012)$ & $(.038)$ & $(.032)$ \\
& & & \\
State FE & $\mathrm{Y}$ & $\mathrm{Y}$ & $\mathrm{Y}$ \\
Observations & 21,152 & 4,722 & 4,722 \\
R-squared & .336 & .391 & .382 \\
\hline
\end{tabular}

Notes: Specifications in columns 2-3 include age, race, number of children, work status (full-time/full-month, part-time/full-month, full-time/part-month, part-time/partmonth), categories of monthly total income $(<\$ 500, \$ 500-\$ 1000, \$ 1000-\$ 1500, \$ 1500$ $\$ 2000$, and $>\$ 2000$ ), state fixed effects, year-specific state unemployment rate (URT) and an interaction between URT and the treatment group indicator. State-clustered standard errors are in parentheses. Full set of covariates are available from the author. 
Table 3: Robustness Check, 1989-1993

\begin{tabular}{llll}
\hline Covered by Private Health Insurance & $(1)$ & $(2)$ & $(3)$ \\
\hline Treat & $-.409^{* * *}$ & $-.487^{* * *}$ & $-.454^{* * *}$ \\
& $(.057)$ & $(.081)$ & $(.068)$ \\
$\mathbb{1}(\mathrm{t}=91,92,93)$ & $-.103^{* * *}$ & $-.078^{* *}$ & $-.083^{* *}$ \\
& $(.033)$ & $(.036)$ & $(.036)$ \\
Treat**1 $(\mathrm{t}=91,92,93)$ & $.080^{*}$ & .059 & $.072^{*}$ \\
& $(.044)$ & $(.042)$ & $(.040)$ \\
& & & \\
Excluding states that adopted welfare waivers & $\mathrm{Y}$ & & \\
Excluding states that had state-level EITCs & & $\mathrm{Y}$ & $\mathrm{Y}$ \\
Including an indicator for high school graduates & & & $\mathrm{Y}$ \\
State FE & $\mathrm{Y}$ & $\mathrm{Y}$ & 4,722 \\
Observations & 3,573 & 4,328 & .340 \\
R-squared & .389 & .387 & .340 \\
\hline
\end{tabular}

Notes: All sample estimates are weighted and every specification includes age, race, number of children, work status (fulltime/full-month, part-time/full-month, full-time/part-month, part-time/part-month), state fixed effects, year-specific state unemployment rate (URT), the interaction term between URT and the treatment group indicator. The numbers in columns 1-2 include categories of monthly total income $(<\$ 500, \$ 500-\$ 1000, \$ 1000-\$ 1500, \$ 1500-\$ 2000$, and $>\$ 2000)$. Column 1 represents the estimate when I drop the single women from states that adopted welfare waivers (i.e., California, Michigan, New Jersey, Oregon and Utah). Column 2 represents the result without the single women from the states that had state-level EITCs (i.e., Minnesota, Wisconsin, Maryland and Rhode Island). Column 3 includes the indicator for high school graduates instead of income categories. State-clustered standard errors are in parentheses. Full set of covariates are available from the author. 
Table 4: Estimates from the Equation (2), 1989-1995

\begin{tabular}{|c|c|c|c|c|c|}
\hline Covered by Private Health Insurance & $(1)$ & $(2)$ & $(3)$ & $(4)$ & $(5)$ \\
\hline & CW (2014) & WLS & OLS & WLS & OLS \\
\hline Relative change due to HITC alone (1985-1993 sample) & $\begin{array}{l}.036^{* * *} \\
(.011)\end{array}$ & & & & \\
\hline Relative change due to HITC alone, $a_{2}=\delta_{4}-\frac{\delta_{5}}{2}$ & & $\begin{array}{l}.058^{* *} \\
(.027)\end{array}$ & $\begin{array}{l}.061^{* * *} \\
(.022)\end{array}$ & $\begin{array}{l}.062^{* *} \\
(.027)\end{array}$ & $\begin{array}{l}.067^{* * *} \\
(.022)\end{array}$ \\
\hline Treat, $\delta_{1}$ & & $\begin{array}{l}-.473^{* * *} \\
(.048)\end{array}$ & $\begin{array}{l}-.475^{* * *} \\
(.047)\end{array}$ & $\begin{array}{l}-.441^{* * *} \\
(.045)\end{array}$ & $\begin{array}{l}-.445^{* * *} \\
(.045)\end{array}$ \\
\hline $\mathbb{1}(\mathrm{t}=91,92,93), \delta_{2}$ & & $\begin{array}{l}-.079^{* * *} \\
(.029)\end{array}$ & $\begin{array}{l}-.093^{* * *} \\
(.025)\end{array}$ & $\begin{array}{l}-.090^{* * * *} \\
(.032)\end{array}$ & $\begin{array}{l}-.104^{* * *} \\
(.028)\end{array}$ \\
\hline $\mathbb{1}(\mathrm{t}=94,95), \delta_{3}$ & & $\begin{array}{l}-.037 \\
(.025)\end{array}$ & $\begin{array}{l}-.047^{*} \\
(.023)\end{array}$ & $\begin{array}{l}-.050^{*} \\
(.028)\end{array}$ & $\begin{array}{l}-.059^{* *} \\
(.026)\end{array}$ \\
\hline Treat $* \mathbb{1}(\mathrm{t}=91,92,93), \delta_{4}$ & & $\begin{array}{l}.070^{*} \\
(.034)\end{array}$ & $\begin{array}{l}.081^{* * *} \\
(.028)\end{array}$ & $\begin{array}{l}.078^{* *} \\
(.036)\end{array}$ & $\begin{array}{l}.092^{* * *} \\
(.028)\end{array}$ \\
\hline Treat $* \mathbb{1}(\mathrm{t}=94,95), \delta_{5}$ & & $\begin{array}{l}.024 \\
(.030)\end{array}$ & $\begin{array}{l}.038 \\
(.026)\end{array}$ & $\begin{array}{l}.031 \\
(.033)\end{array}$ & $\begin{array}{l}.050^{*} \\
(.029)\end{array}$ \\
\hline Including income categories & $\mathrm{Y}$ & $\mathrm{Y}$ & $\mathrm{Y}$ & & \\
\hline Including an indicator for high school graduates & & & & $\mathrm{Y}$ & Y \\
\hline State FE & $\mathrm{Y}$ & $\mathrm{Y}$ & $\mathrm{Y}$ & $\mathrm{Y}$ & Y \\
\hline Observations & 26,796 & 6,495 & 6,495 & 6,495 & 6,495 \\
\hline R-squared & .328 & .395 & .385 & .351 & .345 \\
\hline
\end{tabular}

Notes: All specifications include age, race, number of children, work status (full-time/full-month, part-time/full-month, fulltime/part-month, part-time/part-month), state fixed effects, year-specific state unemployment rate (URT), the interaction term between URT and the treatment group indicator. For a detailed information about the DDD analysis in the first row of column 1, refer to equation (2) and Table 5 in CW. In addition to these control variables, columns 2-3 include categories of monthly total income $(<\$ 500, \$ 500-\$ 1000, \$ 1000-\$ 1500, \$ 1500-\$ 2000$, and $>\$ 2000)$ and columns $4-5$ include the indicator for high school graduates instead of total income categories. State-clustered standard errors are in parentheses. Full set of covariates are available from the author.

This article is protected by copyright. All rights reserved. 
Table 5: Change in Health-Care Utilization \& Self-Reported Health Status

\begin{tabular}{|c|c|c|c|c|c|c|c|c|}
\hline & $(1)$ & $(2)$ & $(3)$ & $(4)$ & $(5)$ & $(6)$ & $(7)$ & $(8)$ \\
\hline & \multicolumn{4}{|c|}{$\begin{array}{l}\text { Annual Office Visit } \\
\text { (Extensive Marqin; \%) }\end{array}$} & \multicolumn{4}{|c|}{$\begin{array}{l}\text { Self-reported health: good/very good } \\
\text { /excellent (not fair or poor) }\end{array}$} \\
\hline & \multicolumn{2}{|c|}{ Equation (1) } & \multicolumn{2}{|c|}{ Equation (2) } & \multicolumn{2}{|c|}{ Equation (1) } & \multicolumn{2}{|c|}{ Equation (2) } \\
\hline Treat & $\begin{array}{l}.056 \\
(.086)\end{array}$ & $\begin{array}{l}.054 \\
(.086)\end{array}$ & $\begin{array}{l}-.039 \\
(.076)\end{array}$ & $\begin{array}{l}-.033 \\
(.076)\end{array}$ & $\begin{array}{l}.061 \\
(.052)\end{array}$ & $\begin{array}{l}.059 \\
(.051)\end{array}$ & $\begin{array}{l}.033 \\
(.049)\end{array}$ & $\begin{array}{l}.034 \\
(.049)\end{array}$ \\
\hline $\mathbb{1}(\mathrm{t}=91,93)$ & $\begin{array}{l}.039 \\
(.043)\end{array}$ & $\begin{array}{l}.038 \\
(.043)\end{array}$ & $\begin{array}{l}.053 \\
(.041)\end{array}$ & $\begin{array}{l}.051 \\
(.041)\end{array}$ & $\begin{array}{l}-.059^{* * * *} \\
(.020)\end{array}$ & $\begin{array}{l}-.063^{* * *} \\
(.020)\end{array}$ & $\begin{array}{l}-.053^{* * *} \\
(.019)\end{array}$ & $\begin{array}{l}-.057^{* * *} \\
(.019)\end{array}$ \\
\hline $\mathbb{1}(\mathrm{t}=94,95)$ & & & $\begin{array}{l}.007 \\
(.040)\end{array}$ & $\begin{array}{l}.002 \\
(.038)\end{array}$ & & & $\begin{array}{l}-.045^{* * *} \\
(.027)\end{array}$ & $\begin{array}{l}-.049 * * * \\
(.028)\end{array}$ \\
\hline Treat $* \mathbb{1}(\mathrm{t}=91,93)$ & $\begin{array}{l}.026 \\
(.049)\end{array}$ & $\begin{array}{l}.026 \\
(.050)\end{array}$ & $\begin{array}{l}.0003 \\
(.044)\end{array}$ & $\begin{array}{l}.002 \\
(.045)\end{array}$ & $\begin{array}{l}.065^{* * *} \\
(.021)\end{array}$ & $\begin{array}{l}.068^{* * *} \\
(.022)\end{array}$ & $\begin{array}{l}.056^{* * *} \\
(.020)\end{array}$ & $\begin{array}{l}.060^{* * *} \\
(.021)\end{array}$ \\
\hline Treat $* \mathbb{1}(\mathrm{t}=94,95)$ & & & $\begin{array}{l}.077^{*} \\
(.041)\end{array}$ & $\begin{array}{l}.081^{*} \\
(.040)\end{array}$ & & & $\begin{array}{l}.021 \\
(.034)\end{array}$ & $\begin{array}{l}.025 \\
(.035)\end{array}$ \\
\hline Relative change due to HITC alone, $a_{2}=\delta_{4}-\frac{\delta_{5}}{2}$ & & & $\begin{array}{l}-.038 \\
(.041)\end{array}$ & $\begin{array}{l}-.038 \\
(.042)\end{array}$ & & & $\begin{array}{l}.046^{* * *} \\
(.016)\end{array}$ & $\begin{array}{l}.047^{* * *} \\
(.017)\end{array}$ \\
\hline Including income categories & Y & & $\mathrm{Y}$ & & $\mathrm{Y}$ & & $\mathrm{Y}$ & \\
\hline Including an indicator for high school graduates & & $\mathrm{Y}$ & & $\mathrm{Y}$ & & $\mathrm{Y}$ & & $\mathrm{Y}$ \\
\hline State FE & $\mathrm{Y}$ & $\mathrm{Y}$ & $\mathrm{Y}$ & $\mathrm{Y}$ & $\mathrm{Y}$ & $\mathrm{Y}$ & $\mathrm{Y}$ & $\mathrm{Y}$ \\
\hline Observations & 3,668 & 3,668 & 4,563 & 4,563 & 3,668 & 3,668 & 4,563 & 4,563 \\
\hline R-squared & .044 & .038 & .038 & .034 & .042 & .047 & .042 & .046 \\
\hline
\end{tabular}

Notes: All sample estimates are weighted and respondents from SIPP-Panel 1992 and 1995 are excluded due to the change in timing of questionnaires about health-care utilization/health status. All specifications include age, race, number of children, work status (full-time/full-month, part-time/full-month, full-time/part-month, part-time/part-month), state fixed effects, year-specific state unemployment rate (URT), the interaction term between URT and treatment group indicator. In addition to these control variables, odd-numbered columns include categories of total income $(<\$ 500, \$ 500-\$ 1000, \$ 1000-\$ 1500, \$ 1500$ $\$ 2000$ and $>\$ 2000)$, while even-numbered columns include the indicator for high school graduates instead of total income. Through columns 1-4, the outcome variable is equal to 1 , if the respondent had visited a doctor's office at least once in a year. Through columns 5-8, the outcome variable is equal to 1 if the respondent answered 3 or above (i.e., 3 'good,' 4 'very good' and 5 'excellent') in the self-reported health status question. Otherwise, this will be 0 (i.e., 2 is 'fair' and 1 is 'bad').

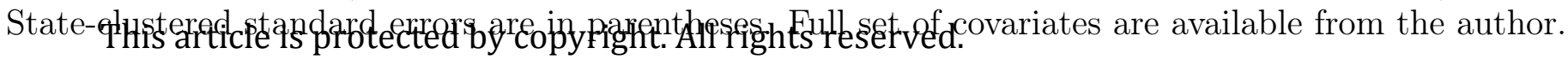




\section{Title Page}

-Title. Effectiveness of Tax Credits for Health Insurance Premium: Evidence from the Health Insurance Tax Credit

\section{- Corresponding author and affiliation.}

DajungJun, jundajun@msu.edu 1-517-582-3962

Department of Economics, Michigan State University, 486 W. Circle Dr., East Lansing, MI 48824, USA 


\section{University Library}

\section{- M M N E R VA A gateway to Melbourne's research publications}

Minerva Access is the Institutional Repository of The University of Melbourne

Author/s:

Jun, D

Title:

Effectiveness of tax credits for health insurance premium: Evidence from the health insurance tax credit

Date:

2018-10

Citation:

Jun, D. (2018). Effectiveness of tax credits for health insurance premium: Evidence from the health insurance tax credit. Health Economics, 27 (10), pp.1609-1616. https:// doi.org/10.1002/hec.3785.

Persistent Link:

http://hdl.handle.net/11343/261074 